\title{
Experimental Research on Seismic Performance of a New-Type of R/C Beam-Column Joints with End Plates
}

\author{
Shufeng Li, Qingning Li, Haotian Jiang, Hao Zhang, and Lizhong Zhang \\ School of Civil Engineering, Xian University of Architecture and Technology, Xi'an 710055, China \\ Correspondence should be addressed to Shufeng Li; 1371757493@qq.com
}

Received 17 March 2017; Accepted 12 April 2017; Published 4 May 2017

Academic Editor: Michele Palermo

Copyright (C) 2017 Shufeng Li et al. This is an open access article distributed under the Creative Commons Attribution License, which permits unrestricted use, distribution, and reproduction in any medium, provided the original work is properly cited.

\begin{abstract}
This paper presents a new-type of fabricated beam-column connections with end plates. The joint details are as follows: the concrete beams are connected to column by end plates and six high strength long bolts passing through the core area. In addition, in order to increase the stiffness and shear strength, stirrups are replaced by the steel plate hoop in the core zone. To examine the fail behavior of the fabricated beam-column connection specimens, a quasi-static test is conducted for nine full-scale models to obtain the hysteresis curves, skeleton curves, ductility, energy dissipation capacity, and other seismic indicators. The experimental results show that all specimens failed in bending in a malleable way with a beam plastic hinge and the hysteresis curves are excellently plump for the end plate connections. From the seismic indexes, the fabricated connection specimens exhibit better seismic performance, which can provide reference for the application of prefabricated frame structure in the earthquake area.
\end{abstract}

\section{Introduction}

The advantages of prefabricated frame structure include simple construction, flexible arrangement, and green environmental protection, which fully reflects the industrial character of modern architecture. In the frame structure, the node plays the role of load transmission, which is the key part of the seismic of structure. The postearthquake investigation found that, in most cases, the collapse of the frame structure is caused by the failure of the node, which shows that the node connection performance reliability of the prefabricated structure is poorer, so their application has been limited in earthquake area. In order to improve the overall seismic performance of the assembly structure, we need to carry on deeper theoretical and experimental research on the assembly node. In recent years, a lot of researches were conducted and achieved notable results. Mao et al. [1] put forward a new combination of bolt end plate connection steel beam-reinforced concrete column node and conduct simulated seismic loading test; the results showed that the steel beam-reinforced concrete column composite joint with high strength bolted end plate was used as a new-type of joint, which has excellent seismic performance and excellent construction performance. A novel type of composite joint was presented by Wang and Zhang [2]; some quasi-static tests were performed on flush and extended end plate joints. These blind bolted end plate composite joints to concretefilled thin-walled steel tubular (CFTST) columns exhibited favorable seismic behavior and energy dissipation capacity. $\mathrm{Wu}$ et al. [3] proposed a new design of bolted beam-tocolumn connections for concrete-filled steel tubes (CFT) and conducted a series of cyclic loading experiments. Experimental results showed that the bolted connections had superior seismic resistance in stiffness, strength, ductility, and energy dissipation mechanisms. From the domestic and foreign researches [4-12], it can be found that the end plate bolt connection applied in steel structure and composite structure has better seismic performance. At present, the researches on the application of end plate bolt connection in concrete structure are less, so the research of seismic performance for such node has practical significance. Besides, prestressed concrete has been widely used in the assembly structure because of its advantages. Some research on unbonded prestressed concrete is conducted by domestic and foreign scholars. The United States early launched a PRESS research program; the experimental study of unbonded prestressed 


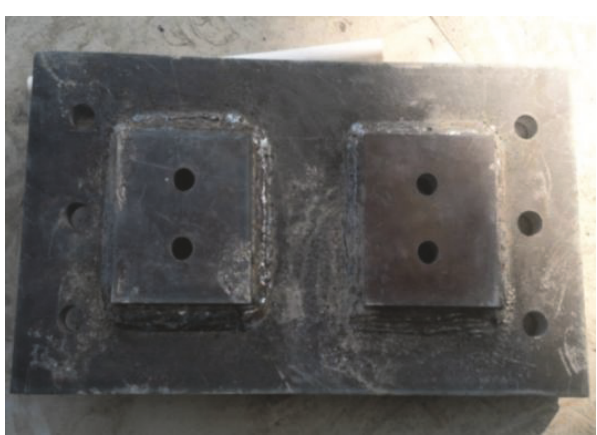

(a) Connection type of end plate and anchor plate

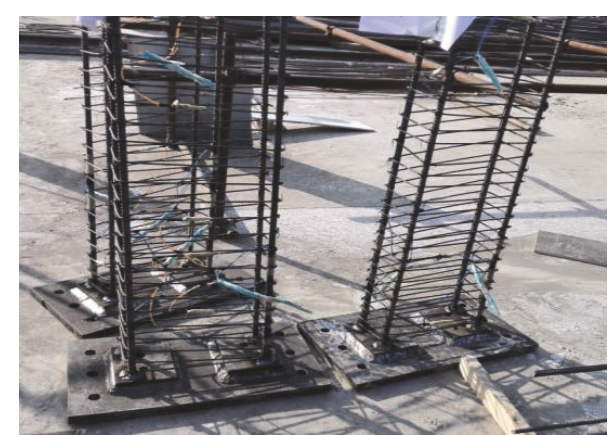

(b) Welding form of normal stirrups and end plate

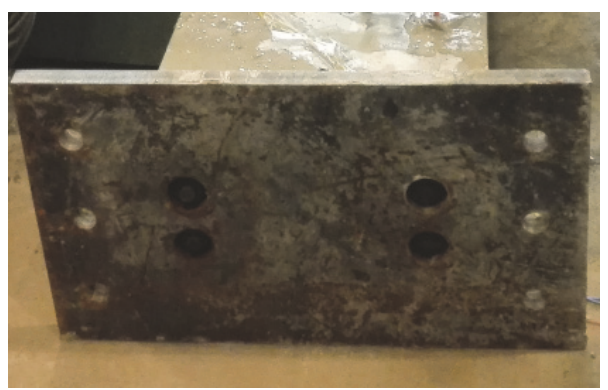

(c) Prestressed reinforcement arrangement form

FIGURE 1: Concrete structure of beam.

frame joints was carried out [13]. The experimental results showed that the unbonded prestressed tendons can significantly reduce the damage degree of the core area in the case of large lateral displacement. The mechanical properties of unbonded prestressed concrete frame joints under low cyclic loading tests were studied by Dong et al. [14]; the results indicated that the unbonded prestressed concrete frame joints have good seismic performance, and the ductility and deformation recovery ability are better than the cast-inplace frame node. Experiments on two concrete joints and two prestressed concrete frame joints were conducted under low frequency cyclic loading by $\mathrm{Fu}$ et al. [15]; the results demonstrated that the residual deformation of prestressed concrete assembly frame joints is less than that of cast in situ concrete joints, and the cracking resisting capacity, stiffness, and deformation recovering capacity of the core joint regions of the assembled specimens are better. From the experimental research, the unbonded prestressed concrete structure has the advantages of strong deformation recovering capacity, better cracking resisting capacity, high stiffness, and ductility. At present, it has been adopted in multistorey and highrise structures, such as Paramount Building, Guangdong International Building, New Century Building, and Nanjing TV Tower. Based on the research results of scholars from different countries and the concept of restricted concrete, a new-type of fabricated beam-column connections with end plates is proposed in this paper. The normal stirrups in the beam and column are replaced by high strength spiral hoop. The partially prestressed concrete beams are adopted in all specimens. For the convenience of construction, the end plate and anchor plate are welded together by groove welding; ordinary reinforcements used in the beam are vertically welded on the end plate by the pier head and prestressed reinforcements passing through anchor plate are anchored inside the end plate by nuts, which can be seen in Figure 1.

\section{Experimental Program}

2.1. Specimens. A total of nine full-scale fabricated beamcolumn connection specimens are selected for the test investigation, where RC-01 is cast-in-place concrete joint. All specimens are expected to exhibit strong-column-weakbeam behavior [16]. Compared with specimens \#PAN-05 and \#PAN-06, double stirrup confined concrete beams are used in the specimens \#PAN-07 and \#PAN-08, and four longitudinal reinforcements with the diameter of $6 \mathrm{~mm}$ are arranged at the four corners of stirrup to fasten the outer stirrup framework, as shown in Figure 3. The diameter of Grade HTH1100 spiral stirrup used in the specimens is $5 \mathrm{~mm}$. The size of end plate is $400 \mathrm{~mm} \times 30 \mathrm{~mm} \times 710 \mathrm{~mm}$. Grade HTH1080 bolts with $27 \mathrm{~mm}$ diameter are used for all connections. Besides, stirrups are replaced by $4 \mathrm{~mm}$ thick steel plate hoop in the core zone. The size and details of all specimens are shown in Figure 2 and listed in Table 1, respectively.

2.2. Material Properties. According to the standard for test method of mechanical properties on ordinary concrete [17], material tests of concrete and high-performance grouting material are performed. Test results indicate that the concrete compressive cube strengths of beam and column are $28 \mathrm{Mpa}$ and $41.9 \mathrm{Mpa}$, respectively. The flexural strength of G-1 high strength grouting material is $3.02 \mathrm{Mpa}$ and the compressive 


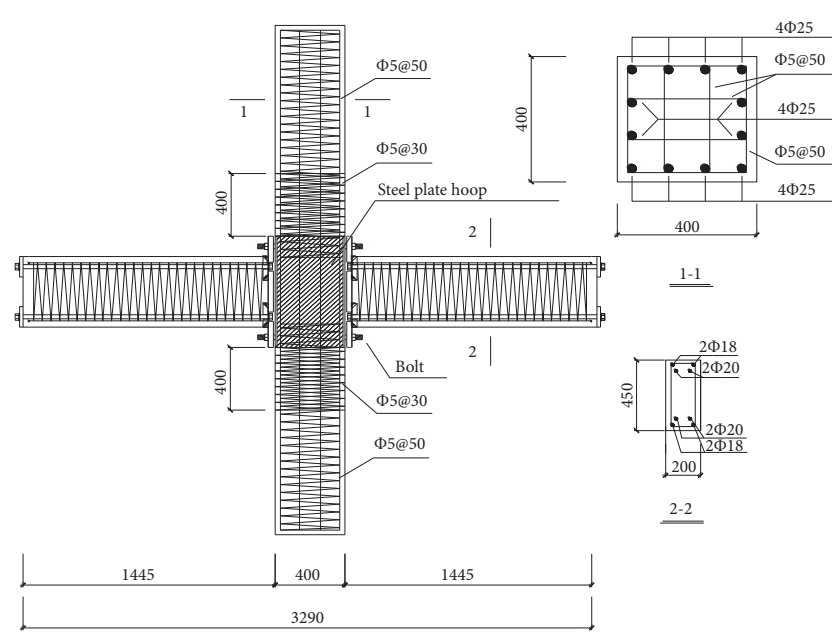

(a) Size and reinforcement of \#PAN-01 06 specimens

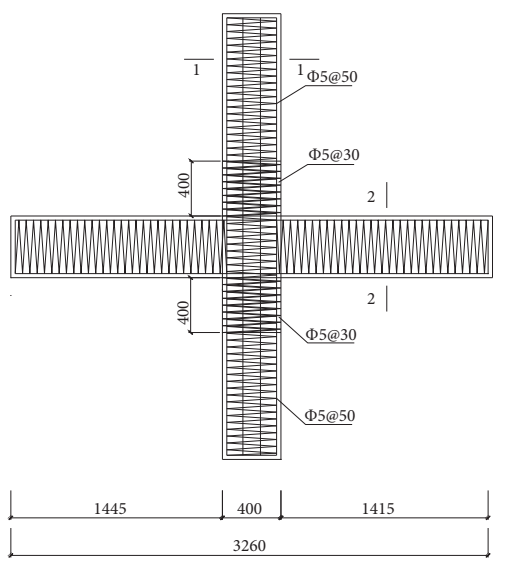

(c) Size and reinforcement of RC-01 specimens

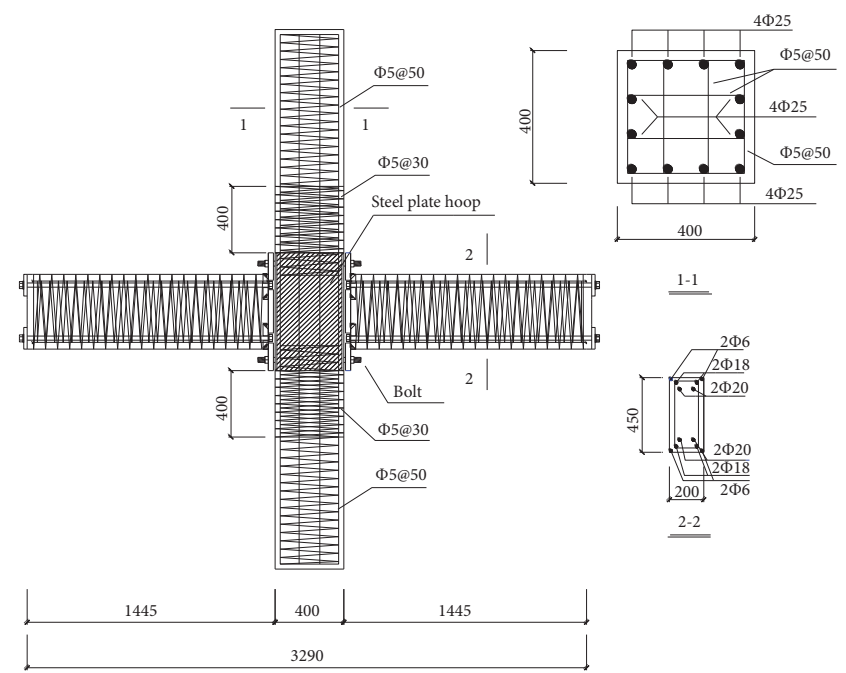

(b) Size and reinforcement of \#PAN-07 08 specimens

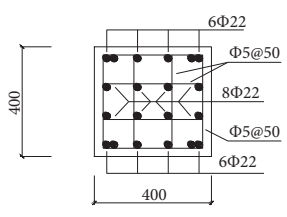

$\underline{\underline{1-1}}$

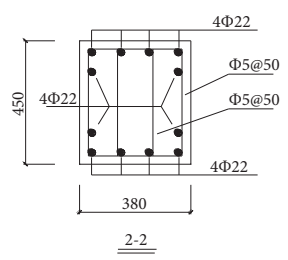

FIGURE 2: Size and reinforcement of specimens (unit: $\mathrm{mm}$ ).

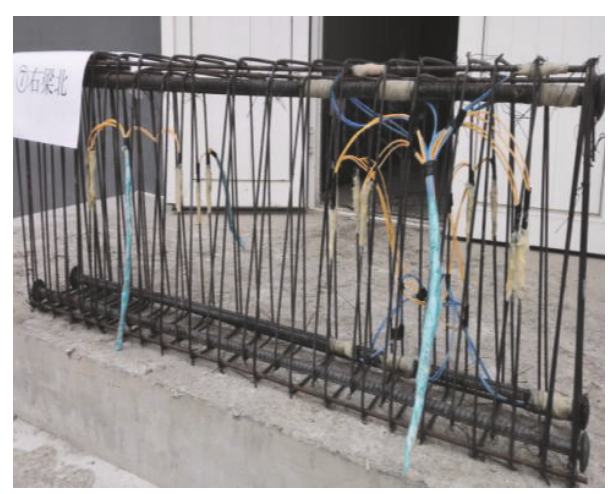

FIGURE 3: Double stirrup arrangement form.

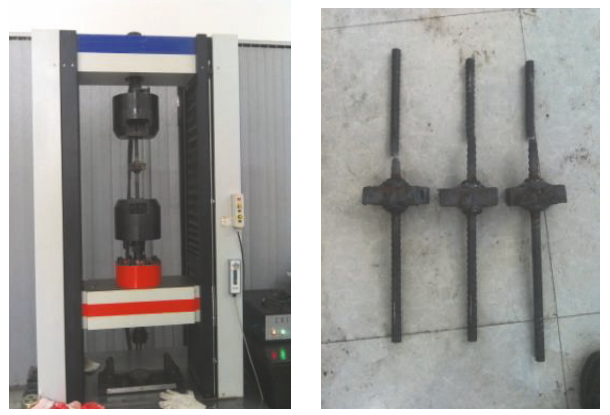

Figure 4: Pier head material test. strength is $41 \mathrm{Mpa}$. Besides, the mechanical properties of longitudinal reinforcement and spiral stirrup are also tested. The test values are listed in Table 2. In addition, the tensile test is conducted for the pier head. The results demonstrate that damage cannot occur at the welded pier head of the ordinary reinforcement, as shown in Figure 4. 
TABLE 1: Arrangement of reinforcement of specimen.

\begin{tabular}{|c|c|c|c|c|c|c|}
\hline Specimen & $\begin{array}{l}\text { Strength of } \\
\text { concrete }\end{array}$ & Section type & $\begin{array}{l}\text { Section size } \\
(\mathrm{mm})\end{array}$ & $\begin{array}{l}\text { Longitudinal } \\
\text { reinforcement }\end{array}$ & Stirrup spacing $(\mathrm{mm})$ & $\begin{array}{l}\text { Stirrup encryption } \\
\text { area }(\mathrm{mm})\end{array}$ \\
\hline Column & C60 & Rectangle & $400 \times 400$ & $16 \Phi 22 \mathrm{HRB} 600$ & 50 & 30 \\
\hline RC-01 & $\mathrm{C} 60$ & Rectangle & $450 \times 380$ & $12 \Phi 22 \mathrm{HRB} 600$ & 50 & 30 \\
\hline \#PAN-01 & C35 & \multirow{8}{*}{ Rectangle } & \multirow{8}{*}{$450 \times 200$} & \multirow{8}{*}{$\begin{array}{c}4 \Phi 20 \mathrm{HTH} 1080 \\
4 \Phi 18 \mathrm{HRB} 400\end{array}$} & 110 & 90 \\
\hline \#PAN-02 & C35 & & & & 50 & 40 \\
\hline \#PAN-03 & C35 & & & & 60 & 50 \\
\hline \#PAN-04 & C35 & & & & 70 & 60 \\
\hline \#PAN-05 & C35 & & & & 90 & 70 \\
\hline \#PAN-06 & C35 & & & & 100 & 80 \\
\hline \#PAN-07 & C35 & & & & 90 (double stirrup) & 70 (double stirrup) \\
\hline \#PAN-08 & $\mathrm{C} 35$ & & & & 100 (double stirrup) & 80 (double stirrup) \\
\hline
\end{tabular}

TABLE 2: Indexes of reinforcement mechanical performance.

\begin{tabular}{|c|c|c|c|c|c|c|}
\hline \multirow{2}{*}{ Material property } & \multicolumn{6}{|c|}{ Diameter } \\
\hline & 5 & 6 & 10 & 18 & 20 & 27 \\
\hline Yield strength/Mpa & 1111.01 & 540.64 & 376.62 & 447.85 & 1160 & 1120 \\
\hline Ultimate strength/Mpa & 1336.7 & 681.98 & 560.17 & 630.72 & 1230 & 1180 \\
\hline Strength-yield ratio & 1.20 & 1.26 & 1.49 & 1.41 & 1.06 & 1.05 \\
\hline Percentage elongation after fracture & 1.2 & 8.24 & 10.36 & 12.47 & 12 & 14 \\
\hline
\end{tabular}

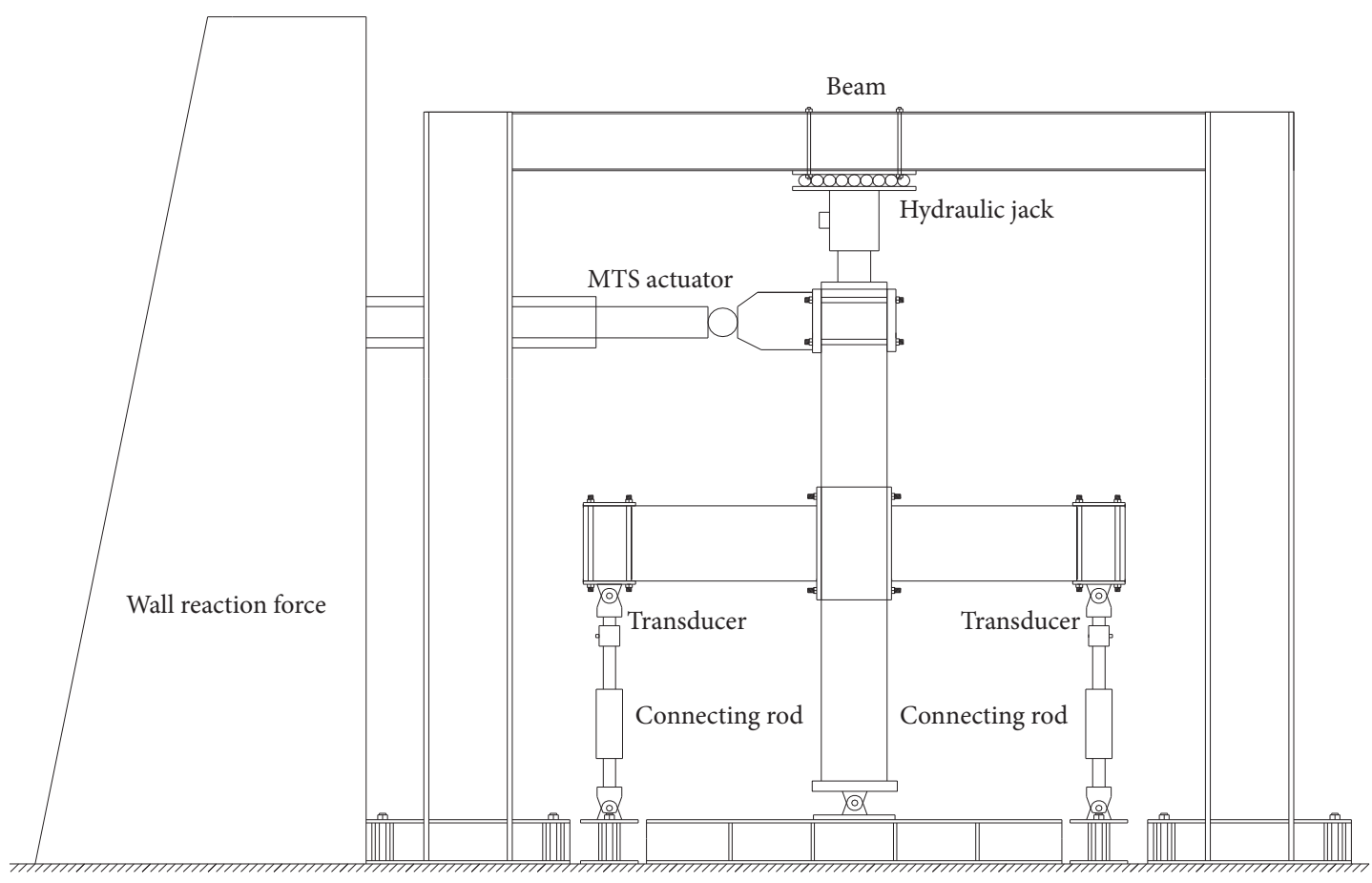

FIGURE 5: Schematic view of the loading device.

\section{Test Loading Device and History}

In this test, pseudo static cyclic loading is used and loading method of column end is adopted. The schematic diagram of loading device is shown in Figure 5. The test setup consists of a $100 \mathrm{~T}$ horizontal actuator applied at the column end and a $500 \mathrm{kN}$ capacity hydraulic jack positioned vertically at the top of column. All specimens are subjected to an constant axial load of $800 \mathrm{kN}$ at the top of the column through the hydraulic jack placed on the column top. Based on the Specification 

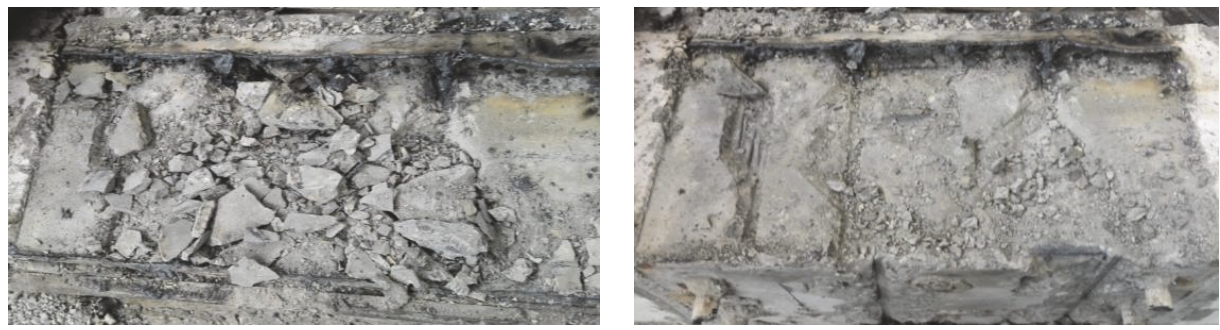

FIGURE 6: Internal damage state of node core area.

of Test Methods for Earthquake Resistant Building [18], the mixed load method of load and displacement is used in this test. The load-control is adopted and repeated once at each control point before the specimens yielded. The displacement control is used and repeated three times after the specimens yielded.

\section{Analysis on Test Results}

4.1. Test Process. Under the action of low frequency cyclic loading, the shear failure occurs in the core area of the RC-01 because of the fault of the design, and the bending failure of beam end occurs to the \#PAN series test specimen of monolayer stirrup with the similar destruction process. When the cracking load is reached, the vertical bending cracks appear in the beam region close to the core area, the crack width is about $0.05 \mathrm{~mm}$, and it is completely closed after unloading. As the load increases, there are more cracks, whose length and width increase constantly with the oblique trend, and the distribution range gradually spreads away from the core zone. When reaching the yield load, the width of maximum crack is about $0.2 \mathrm{~mm}$. In the stage of displacement control, the concrete protective layer falls off, but the concrete internal damage is not serious, which shows that the specimens have good deformation performance. When the horizontal displacement reaches about $150 \mathrm{~mm}$, the bearing capacity of the joint decreases to $85 \%$ of the peak load, and the specimens have a visible plastic hinge destruction zone, and the test is stopped. The failure modes of double-layer stirrup specimens \#PAN-07 and \#PAN-08 and monolayer stirrup specimens are basically identical. The cracking load and ultimate load of the double ring specimen are relatively high; double ring specimens have small damage region at the same time; the main reason is that outer stirrup can better restrain concrete cover, which indicates that double-layer stirrups have a remarkable impact on concrete core. During the whole process of the test, there is no sign of separation between the end plate and the column and no buckling occurring to the end plate. The node core zone is in the state of three-dimensional stress under the restraint of steel plate hoop and there is no shear failure as well as slippage happening. After the test, it is found that the concrete cover of the joint core area is shed, but there are no obvious cracks inside the concrete, which can be seen in Figure 6 . No fracture and sealing off occur at the pier head between nonprestressed reinforcement and end plate. In addition, for specimen \#PAN-02, slippage occurs to the pedestal during the loading because of the equipment problems, positive displacement, and negative displacement are asymmetric. Later, equipment is set again and reinforcing specimen is loaded again. For \#PAN-06 and \#PAN-07, in the load process, the prestressed tendons are separated from the nuts at $1 \Delta_{y}$ and $4 \Delta_{y}$, respectively, where $\Delta_{y}$ is the yield displacement, for which the main reason is the fact that the length of the thread between prestressed reinforcement and nut is not enough. Compared with other test specimens, the specimens are suggested keeping at least three threads. Figure 7 shows the final damage state of different test specimens.

4.2. Hysteresis Curve. The recorded force-displacement hysteresis curves for all specimens are shown in Figure 8. The hysteresis curve of the RC-01 shows a certain pinch phenomenon because the shear failure occurs in the core area. However, the specimen has a certain bearing capacity after falling off of concrete cover and there is no phenomenon of mutation of bearing capacity, which indicates that high strength spiral stirrups can provide a better constraint effect for concrete core. For the fabricated node specimens, during the initial loading, the hysteretic curves are in the elastic stage and there are hardly residual deformations after unloading. With the cyclic increasing, the vertical bending cracks appear in the beam end; however because of the influence of the prestressed reinforcement, residual deformations are very small corresponding to unloading. After the nonprestressed reinforcement yielded, the following hysteresis curve is carried out under displacement control; there is no obvious bearing capacity drop in the cycles of the same displacement and the hysteresis loop is plump and stable, so the specimens have good energy dissipation capacity. When the specimens are close to failure, the bearing capacity has no obvious decrease after reaching the peak point; the main reason is that, under the constraint of the high strength spiral stirrup, the internal core concrete on the beam end can still bear a certain load. From the cyclic curves of \#PAN-07 and \#PAN08 , the force-displacement hysteresis curves are plump; the specimens exhibit higher bearing capacity and better seismic performance.

4.3. Skeleton Curve. The skeleton curve derived from the hysteresis curve is a valuable tool for quantifying seismic performance index. Figure 9 shows the backbone curves of all test specimens. As can be seen from Figure 9, the skeleton curves of all fabricated node specimens show the same tendency. The backbone curves increase linearly before 


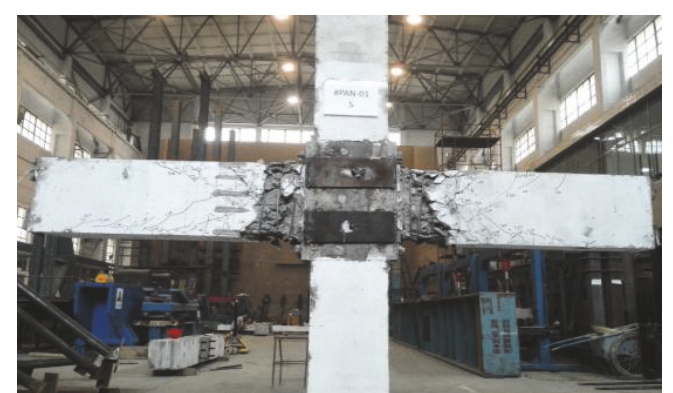

(a) \#PAN-01 ultimate failure diagram

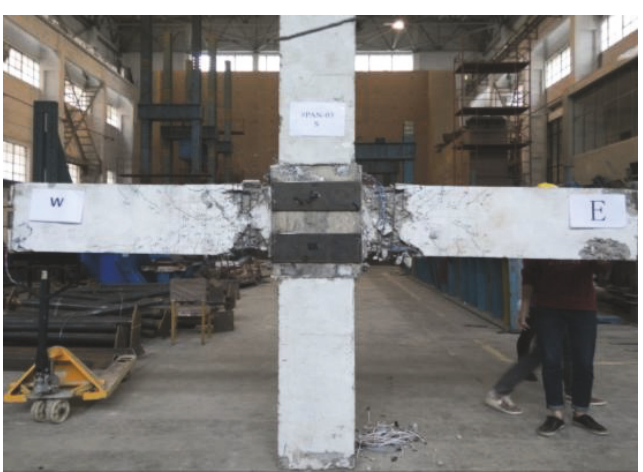

(c) \#PAN-03 ultimate failure diagram

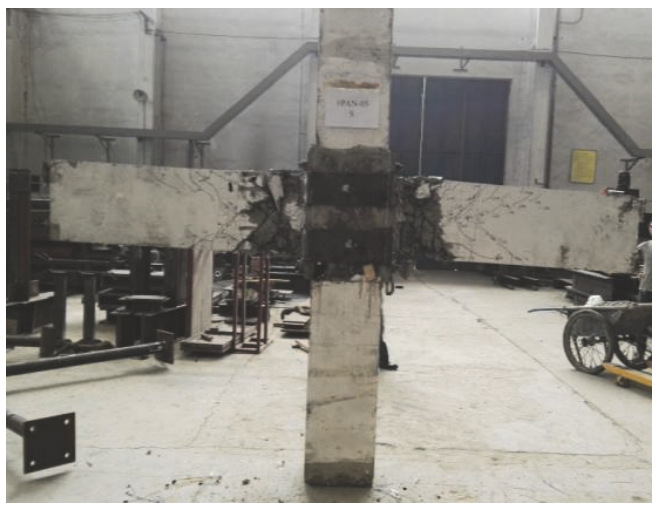

(e) \#PAN-05 ultimate failure diagram

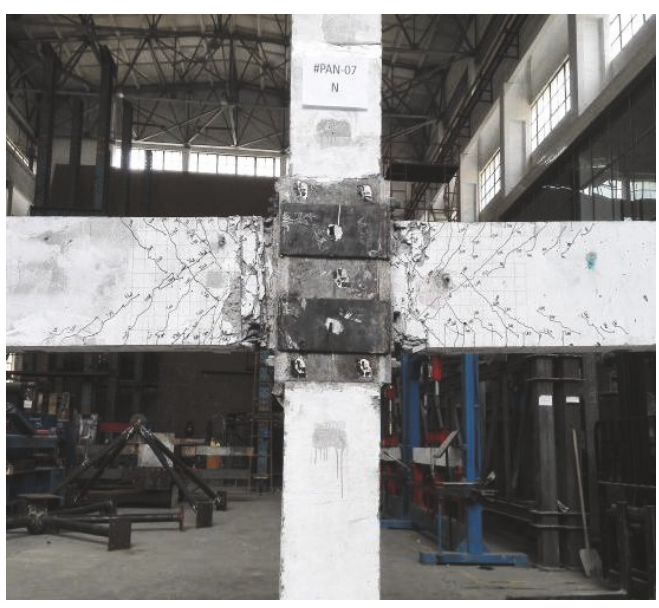

(g) \#PAN-07 ultimate failure diagram

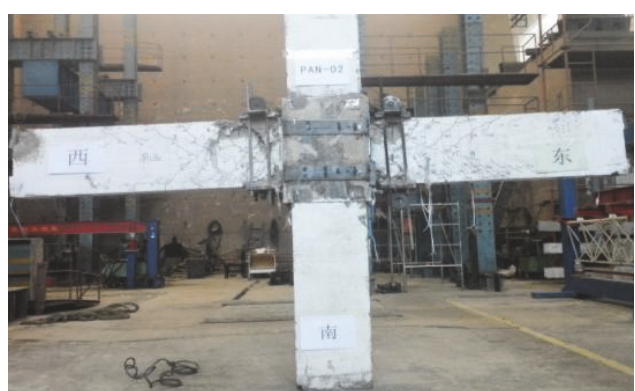

(b) \#PAN-02 ultimate failure diagram

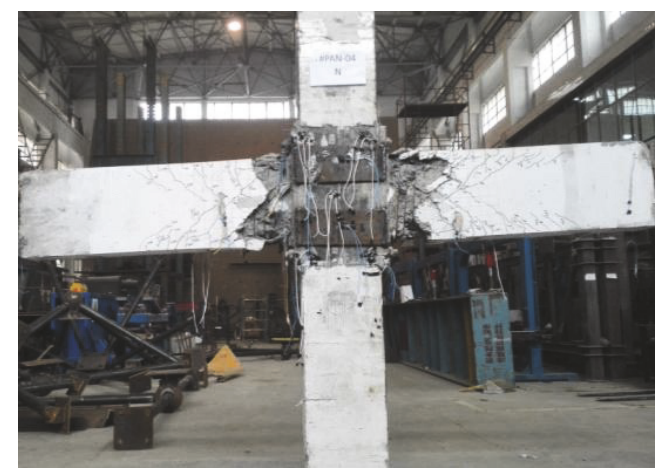

(d) \#PAN-04 ultimate failure diagram

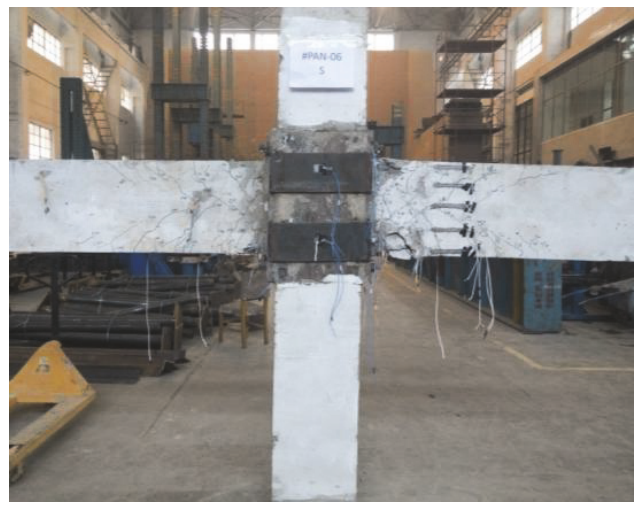

(f) \#PAN-06 ultimate failure diagram

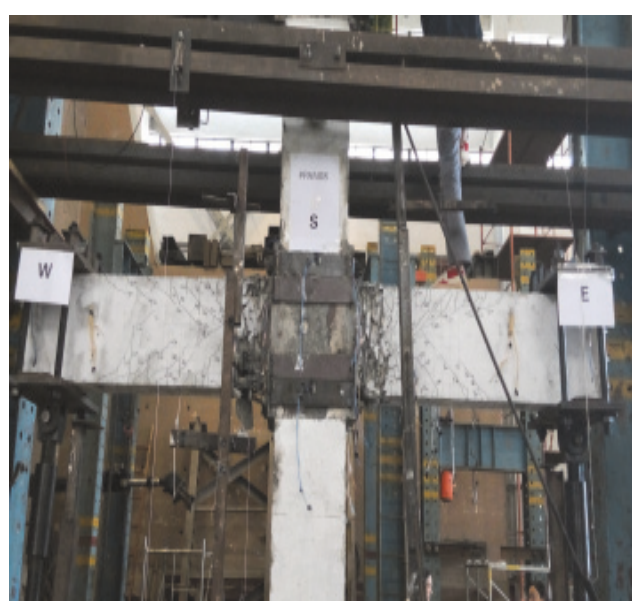

(h) \#PAN-08 ultimate failure diagram

Figure 7: Continued. 


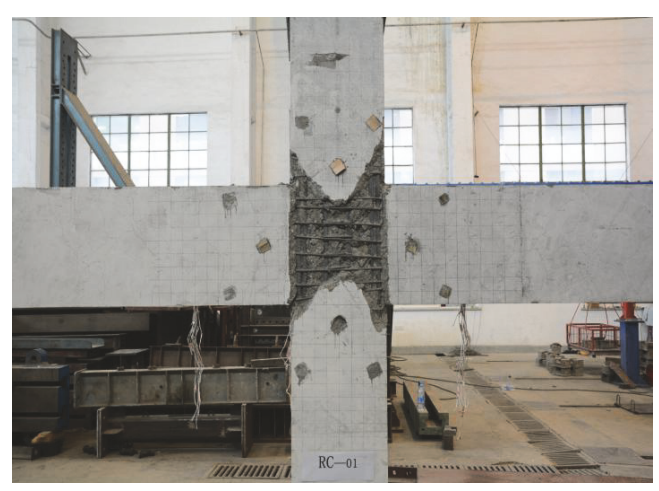

(i) RC-01 ultimate failure diagram

FIGURE 7: Specimens ultimate failure modes.

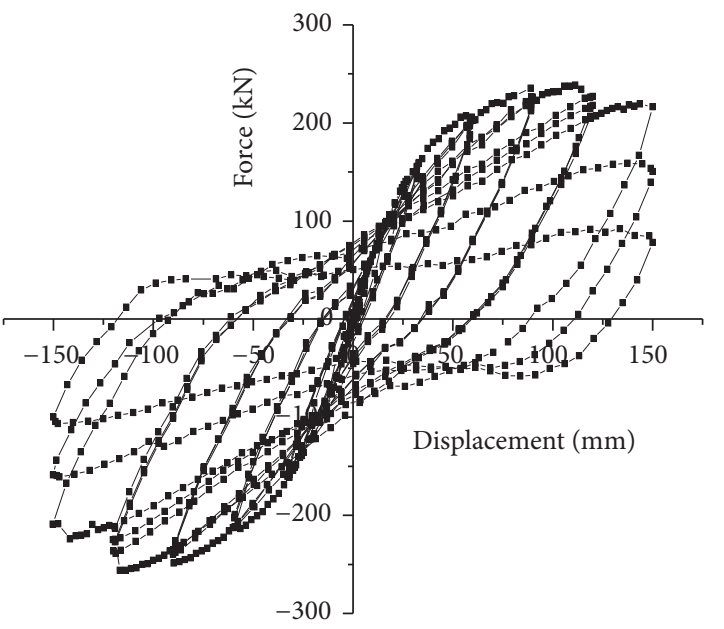

-- \#PAN-01

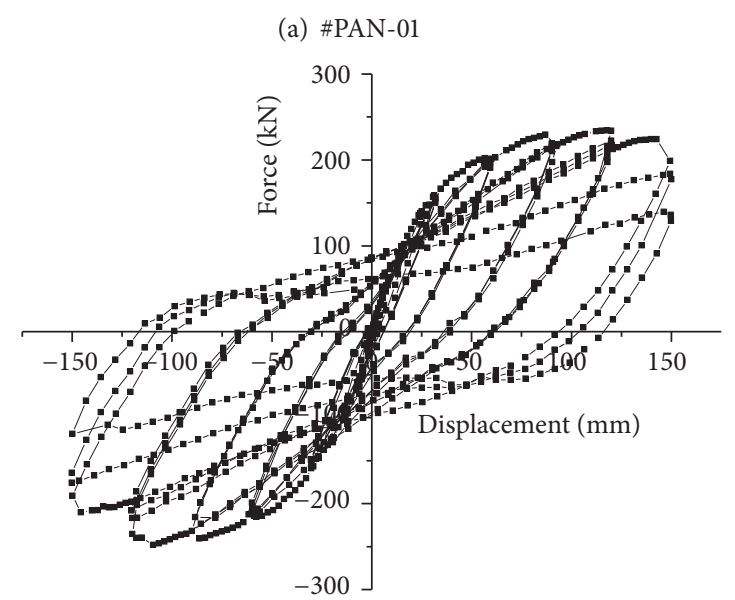

-.- \#PAN-03

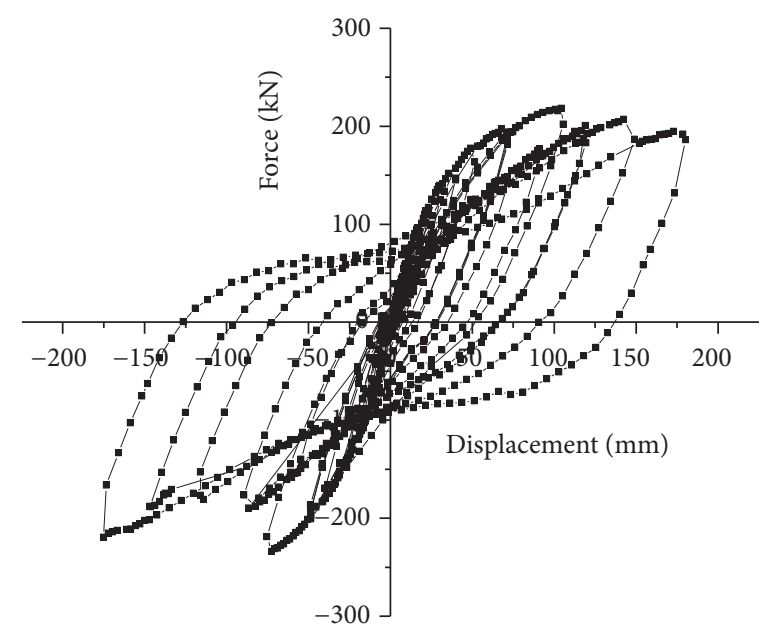

-.- \#PAN-02

(b) \#PAN-02

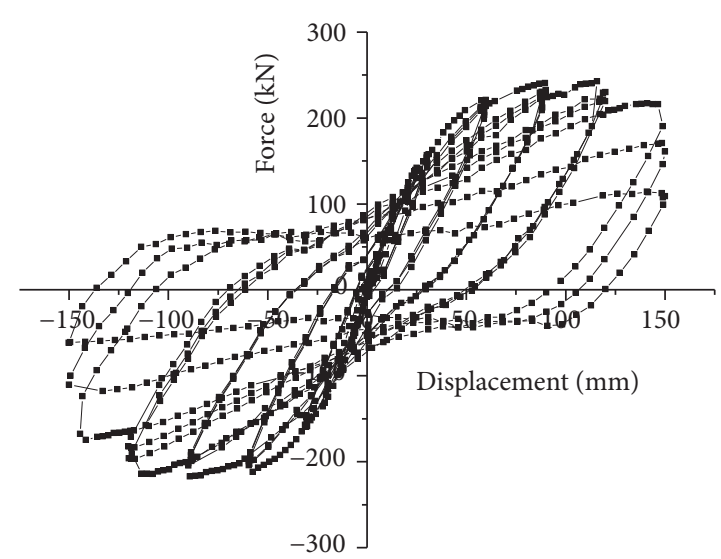

-.- \#PAN-04

(d) \#PAN-04

(c) \#PAN-03

Figure 8: Continued. 

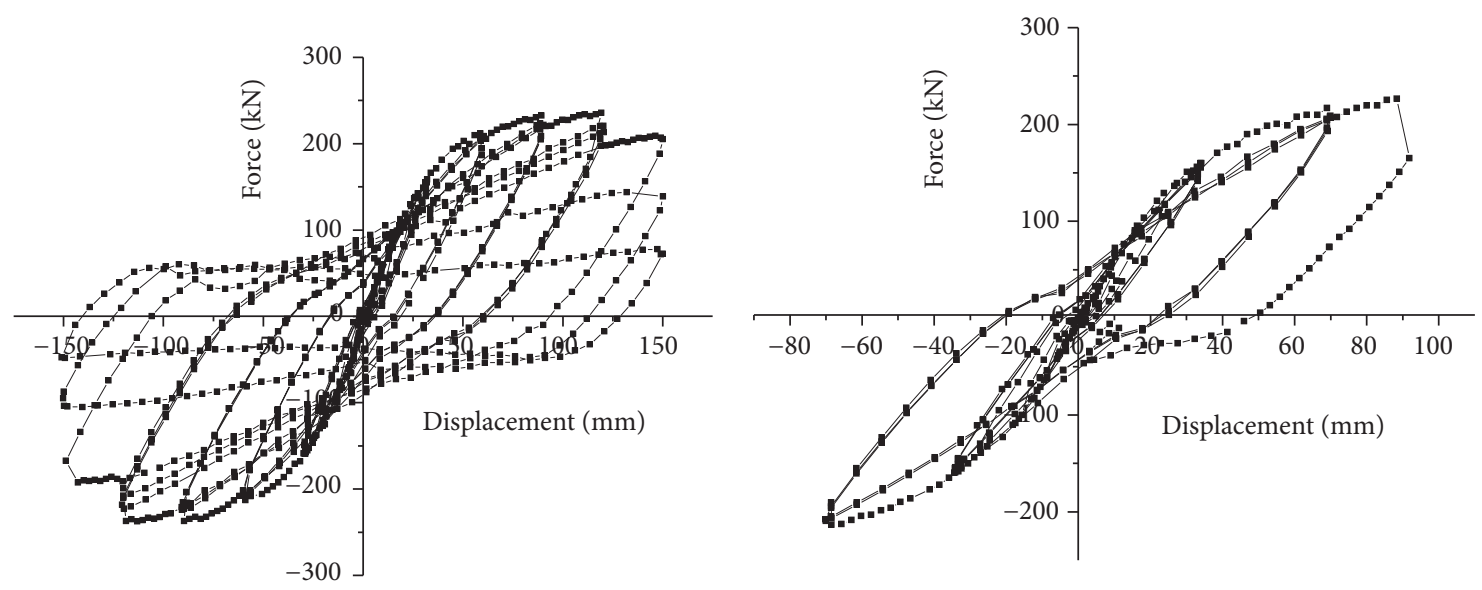

-.- \#PAN-05

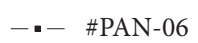

(e) \#PAN-05

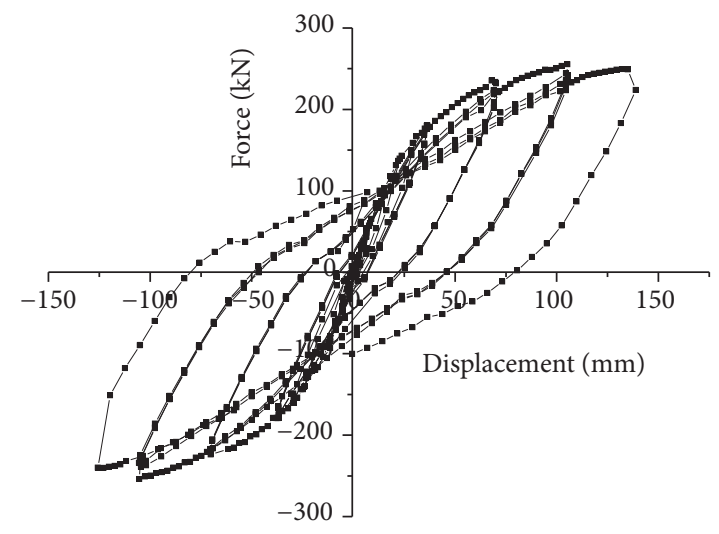

-.- \#PAN-07 (f) \#PAN-06

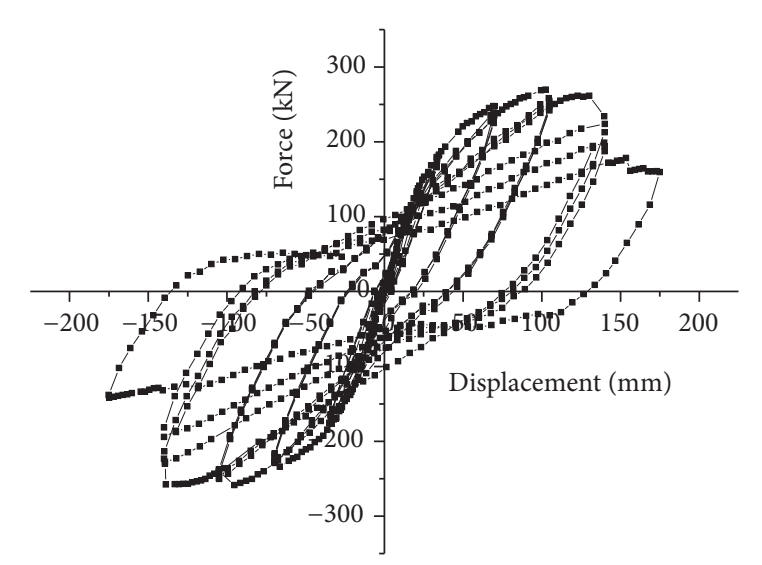

-. \#PAN-08

(h) \#PAN-08

(g) \#PAN-07

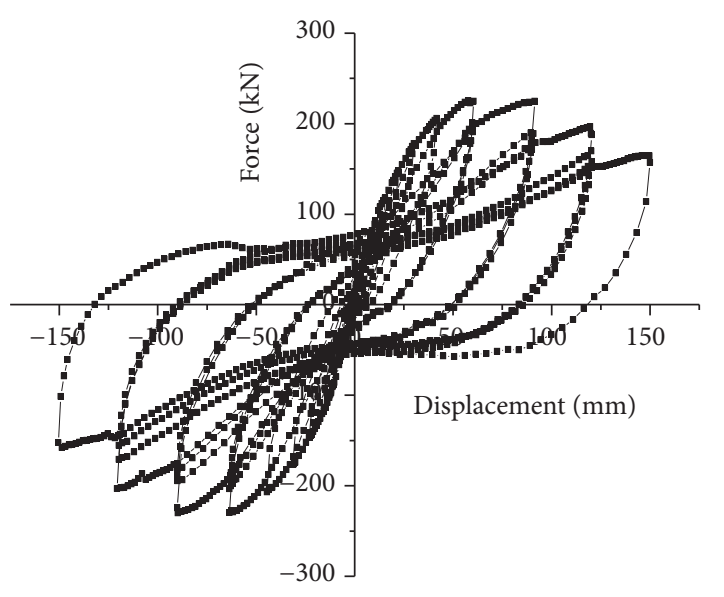

-.- RC-01

(i) RC-01

Figure 8: $P-\Delta$ curve of specimens. 


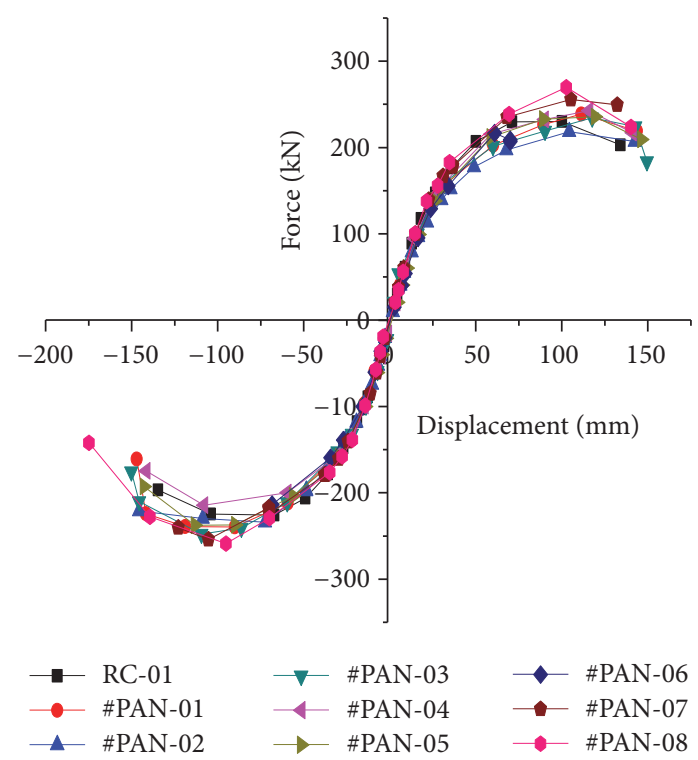

FIGURE 9: Skeleton curve of specimens.

the specimens yielded. Under the control of large displacement, there is no obvious bearing capacity degeneration and the limit displacement point is far away from the yield displacement point, which shows that the assembly joint has good deformation performance [19]. There is no big difference among the limit bearing capacity of the specimens; the main reason is that the final failure modes of all fabricated specimens are beam end bending failure instead of shear failure, which shows that the high strength spiral stirrup can better confine concrete and greatly improve the shear bearing capacity of the cross section. Conclusion can be made from skeleton curves of \#PAN-07 and \#PAN-08 that double-layer spiral stirrups used in the beam have remarkable influences on the bearing capacity.

4.4. Stiffness Degeneration. Stiffness degeneration refers to the phenomenon that the horizontal lateral resistant force decreases as the number of cycle goes up while maintaining the same peak displacement. The beam-column node is the key of the structural force transmission, whose degree of stiffness degeneration has a great influence on the overall structure seismic performance. The stiffness degeneration of the structural member can be obtained by the coefficient of bearing capacity decrease, which can be seen in (1), where $P_{j}{ }^{i}$ is the load value under the $i$ th cycle when the relative lateral displacement $\Delta / \Delta_{y}$ is $j ; P_{j}{ }^{1}$ is the maximum load when $\Delta / \Delta_{y}$ is $j$.

$$
\lambda_{i}=\frac{P_{j}{ }^{i}}{P_{j}{ }^{1}} .
$$

Figure 10 presents the stiffness degeneration of prefabricated joints, where $\Delta_{y}$ is the displacement corresponding to the yield load; it can be seen that the prefabricated nodes have a longer horizontal branch after the test specimens

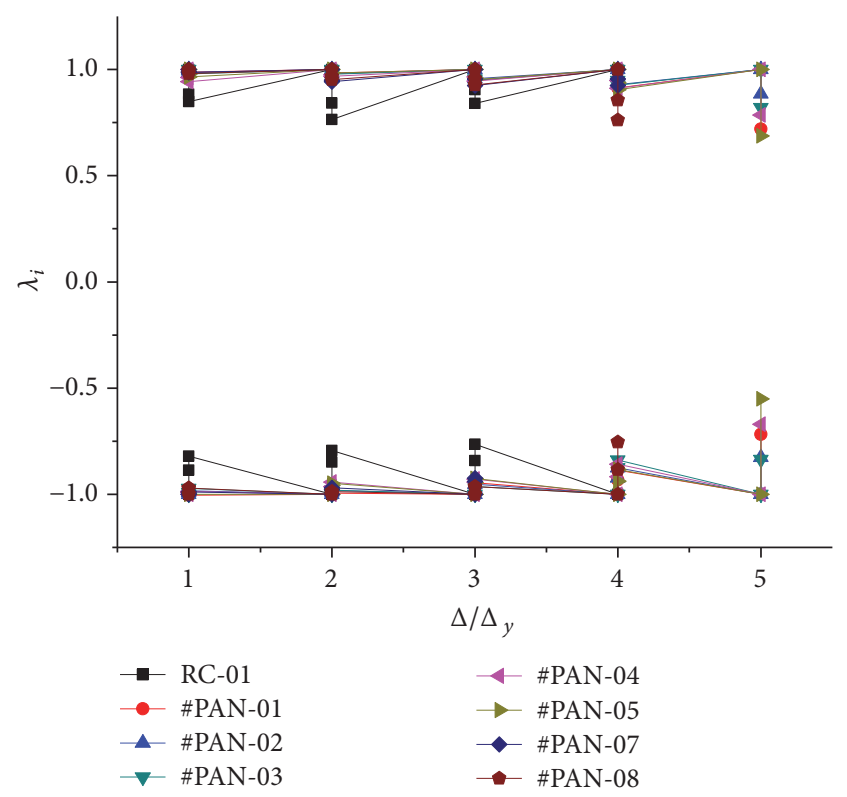

FIGURE 10: Strength degradation curve of specimens.

yielded. When approaching damage, the cracks of the beam end plastic hinge region develop fully, the concrete protective layer falls off, and the strength decreases greatly. However, the stiffness degeneration coefficient of the specimens is beyond 0.9 and the specimens can bear certain load when destruction happens, which can play a better seismic behavior.

4.5. Ductility Capacity. Ductility capacity is an important parameter for evaluating structure seismic capacity.

The ductility coefficient $\mu$ is defined as the ratio of limit displacement $\Delta_{u}$ to yielding displacement $\Delta_{y}$; the ultimate displacement is the corresponding displacement values when the bearing capacity drops to $85 \%$ of peak value, and the yield displacement is determined according to equivalent energy method [20]. The ductility coefficients of the specimens are shown in Table 3.

From Table 3, the ductility coefficient of the prefabricated nodes is between 2.5 and 3.4 and the previous test's ductility coefficient of the cast in situ reinforced concrete frame node is around 2.0 and $5.5[21,22]$. In this test, the ductility coefficients of the prefabricated nodes are in the scope, showing the prefabricated joint has good deformation. Although the shear failure occurs in node core area, RC-01 exhibits better ductility under the constraint of high strength spiral stirrup, which demonstrates that the high strength spiral stirrup has a satisfactory effect on concrete.

4.6. Energy Dissipation. When the structure enters the elastic-plastic stage, the component's energy dissipating capacity determines the seismic performance of the structure to a great extent and in the test, how much energy the component can be absorbed is reflected by the area surrounded by load-displacement curve. In this paper, the component's energy dissipation is evaluated by equivalent viscous coefficient $h_{e}$. The calculation formulas of equivalent 
TABLE 3: Load characteristic values and displacement ductility of specimens.

\begin{tabular}{|c|c|c|c|c|c|c|}
\hline \multicolumn{2}{|c|}{ Specimen number } & \multirow{2}{*}{$\begin{array}{c}\text { Yield load } \\
P_{y} / \mathrm{kN}\end{array}$} & \multirow{2}{*}{$\begin{array}{l}\text { Yield displacement } \\
\qquad \Delta_{y} / \mathrm{mm} \\
36.26\end{array}$} & \multirow{2}{*}{$\begin{array}{c}\text { Limit load } \\
P_{u} / \mathrm{kN}\end{array}$} & \multirow{2}{*}{$\begin{array}{c}\text { Ultimate } \\
\text { displacement } \\
\Delta_{u} / \mathrm{mm} \\
132.91\end{array}$} & \multirow{2}{*}{$\begin{array}{c}\text { Ductility factor } \\
\mu \\
3.67\end{array}$} \\
\hline RC-01 & Front & & & & & \\
\hline साप- & Back & -194.51 & -38.39 & -232.22 & -134.07 & 3.49 \\
\hline \multirow{2}{*}{ \#PAN-01 } & Front & 178.17 & 52.88 & 238.57 & 143.67 & 2.73 \\
\hline & Back & -181.16 & -50.84 & -256.12 & -141.66 & 2.79 \\
\hline \multirow{2}{*}{ \#PAN-02 } & Front & 164.75 & 53.15 & 230.93 & 141.13 & 2.66 \\
\hline & Back & -180.91 & -50.24 & -233.97 & -146.83 & 2.92 \\
\hline \multirow{2}{*}{ \#PAN-03 } & Front & 175.72 & 48.26 & 234.51 & 149.47 & 3.10 \\
\hline & Back & -185.20 & -57.05 & -247.91 & -145.67 & 2.55 \\
\hline \multirow{2}{*}{ \#PAN-04 } & Front & 180.63 & 55.23 & 242.66 & 148.54 & 2.69 \\
\hline & Back & -160.56 & -42.21 & -211.84 & -141.47 & 3.35 \\
\hline \multirow{2}{*}{ \#PAN-05 } & Front & 175.01 & 54.47 & 232.70 & 146.39 & 2.69 \\
\hline & Back & -167.47 & -47.66 & -237.11 & -142.75 & 3.00 \\
\hline \multirow{2}{*}{ \#PAN-07 } & Front & -201.46 & 50.30 & 255.515 & 145.12 & 2.89 \\
\hline & Back & -199.78 & -53.76 & -254.04 & -140.85 & 2.62 \\
\hline \multirow{2}{*}{ \#PAN-08 } & Front & 199.06 & 56.06 & 269.87 & 142.04 & 2.53 \\
\hline & Back & -192.31 & -53.19 & -258.73 & -139.86 & 2.63 \\
\hline
\end{tabular}

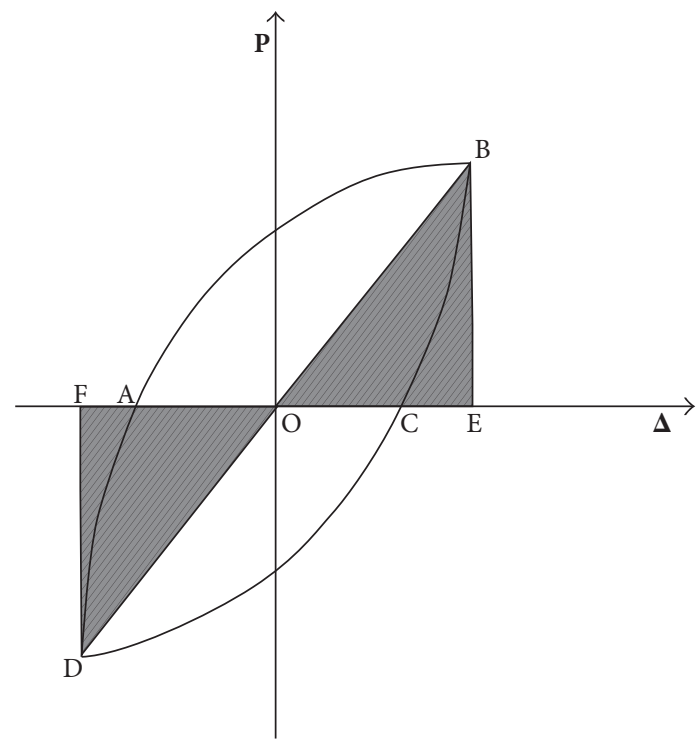

FIGURE 11: Hysteresis loop energy.

viscous coefficient can be seen in (2), where $S_{\mathrm{ABCD}}$ is the area of hysteretic loop; $S_{\mathrm{OBE}}$ and $S_{\mathrm{ODF}}$ are areas within $\mathrm{OBE}$ and ODF, as shown in Figure 11.

$$
h_{e}=\frac{1}{2 \pi} \frac{S_{\mathrm{ABCD}}}{S_{\mathrm{OBE}}+S_{\mathrm{ODF}}} .
$$

Figure 12 shows the equivalent viscous damping coefficient of all specimens; during the initial loading, the prefabricated node is in the elastic stage; it has good deformation restoring capacity and smaller energy consumption. After the nonprestressed reinforcement yielded, the residual deformation

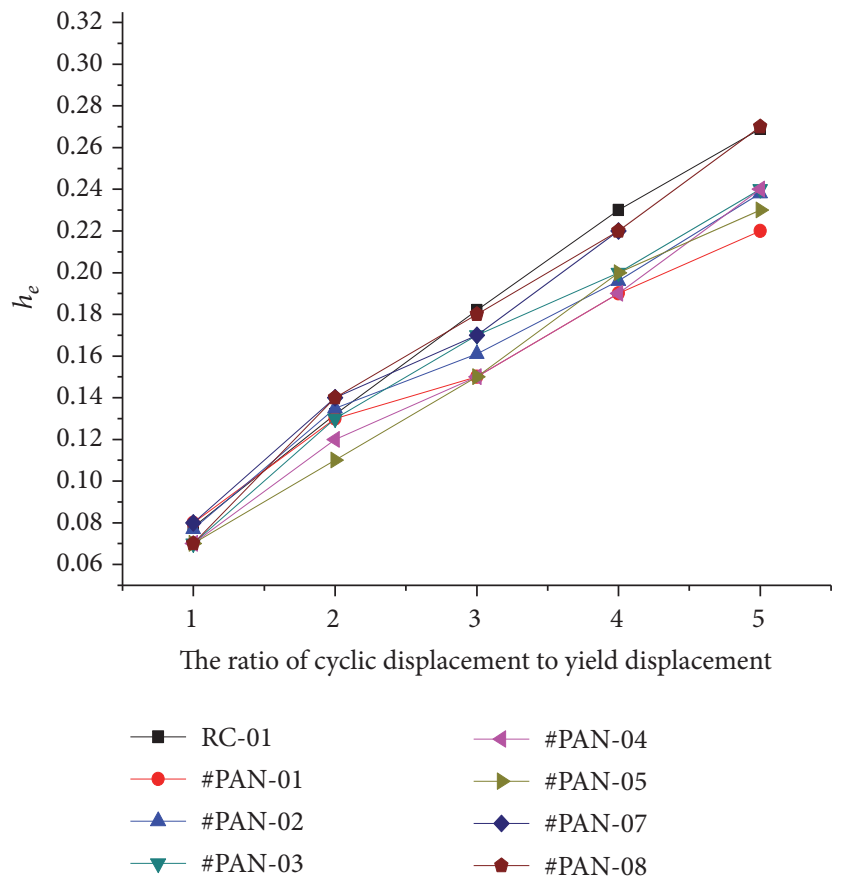

FIGURE 12: Equivalent viscous damping coefficient.

appears and equivalent viscous coefficient increases obviously. The equivalent viscous coefficient of the cast-in-place concrete node is about 0.10 when reaching peak load [23]. The equivalent viscous coefficient of each prefabricated node is between 0.22 and 0.24 , showing that the energy consumption capacity of the prefabricated node is superior to standard test specimens of the cast in situ concrete. For the double stirrup 
specimens, there is bigger energy consumption capacity and its equivalent viscous coefficient is about 0.27 .

\section{Conclusion}

A new-type of fabricated beam-column connection with end plates is presented. To investigate the seismic behavior of the prefabricated node, a quasi-static test is conducted for nine real-size beam-column connections. From the experimental results, the following conclusions can be drawn.

(1) From the seismic performance indices such as strength, ductility factor, and energy dissipation capacity, the strength degradation of the fabricated joint is not obvious, and the joint proposed in this paper exhibits favorable ductility and energy dissipation capacity.

(2) Under the constraint of the double-layer stirrup, \#PAN-07 and \#PAN-08 have larger bearing capacity, ductility, and energy dissipation capacity. When the plastic hinge failure appears in the beam end, the damage area is small and drop-out of concrete protective layer is not serious. So it is suggested that the double-layer stirrup can be arranged in the hinge region to improve the seismic performance of the structure.

(3) In this test, there are no fracture and sealing off in the weld pier head used in between ordinary reinforcement and end plate, so this connection form can achieve the purpose of force transmission under the action of load, which can be applied in practical engineering.

\section{Conflicts of Interest}

The authors declare that they have no conflicts of interest.

\section{References}

[1] W. F. Mao, Y. T. Wu, and Y. Xiao, "Experimental research on seismic behavior of bolted steel beam to RC column connections," Industrial Construction, vol. 35, no. 11, pp. 1-4, 2005.

[2] J. Wang and H. Zhang, "Seismic performance assessment of blind bolted steel-concrete composite joints based on pseudodynamic testing," Engineering Structures, vol. 131, pp. 192-206, 2017.

[3] L.-Y. Wu, L.-L. Chung, S.-F. Tsai, T.-J. Shen, and G.-L. Huang, "Seismic behavior of bolted beam-to-column connections for concrete filled steel tube," Journal of Constructional Steel Research, vol. 61, no. 10, pp. 1387-1410, 2005.

[4] J. H. Khoo, B. Li, and W. K. Yip, "Tests on precast concrete frames with connections constructed away from column," ACI Structural Journal, vol. 61, no. 1, pp. 18-27, 2006.

[5] B.-S. Han, S.-W. Shin, and B.-Y. Bahn, "A model of confined concrete in high-strength reinforced concrete tied columns," Magazine of Concrete Research, vol. 55, no. 3, pp. 203-214, 2003.

[6] H. H. Korkmaz and T. Tankut, "Performance of a precast concrete beam-to-beam connection subject to reversed cyclic loading," Engineering Structures, vol. 27, no. 9, pp. 1392-1407, 2005.

[7] B. Marco, G. Santino, and T. Mauro et al., "Beam-column joints in continuous RC frames: comparison between cast-in-situ and precast solutions," Engineering Structures, vol. 127, pp. 129-144, 2016.

[8] K. S. Al-Jabri, P. Pillay, M. B. Waris, and T. Pervez, "Modeling of composite beam-column flexible endplate joints at elevated temperature," Composite Structures, vol. 143, pp. 180-188, 2016.

[9] H. Jiang, Q. Li, W. Jiang, and D.-Y. Zhang, "Study on seismic performance of connection joint between prefabricated prestressed concrete beams and high strength reinforcementconfined concrete columns," Steel and Composite Structures, vol. 21, no. 2, pp. 343-356, 2016.

[10] X. Li, Y. Xiao, and W. F. Mao et al., "Experimental research on seismic behavior of reinforced concrete column-to-steel beam joints with bolted end-plate," Journal of Hunan University: Natural Science Edition, vol. 21, no. 2, pp. 1-5, 2007.

[11] Q. N. Li, X. C. Zheng, and M. T. Xu et al., "Experimental research and theoretical analysis of a new connection node with steel plate hoop and bolt tendons," Industrial Building, vol. 43, no. 9, pp. 59-64,87, 2013.

[12] B. Liu, Y. Z. Zhang, and Z. F. Jin et al., "Experimental study on Seismic Behavior of prestressed fabricated PC frame connections," JournaI of Building Structures, vol. 26, no. 2, pp. 60-65, 116, 2005.

[13] M. J. N. Priestley, "The PRESSS program-current status and proposed plans for Phase III," PCI Journal, vol. 41, no. 2, pp. $22-$ 40, 1996.

[14] T. F. Dong, Z. B. Li, X. Y. Zhou, and L. F. Feng, "Experimental study on seismic performances of precast prestressed concrete beam-to-column connections with unbonded tendons," Journal of Beijing University of Technology, vol. 32, no. 2, pp. 144-148,154, 2006.

[15] X. Y. Fu, Y. Y. Yu, J. Q. Han, and X. D. Hong, "Experimental study on seismic behavior of interior joints in prestressed concrete assembly frame," Journal of Building Structures, vol. 36, pp. $203-$ 208, 2015.

[16] GB50010-2010, Code for Design of Concrete Structures, China Architecture and Building Press, Beijing, China, 2010.

[17] GB/T50081-2002, "Standard for Test Method of Mechanical Properties on Ordinary Concrete".

[18] JGJ/T 101-2015, Specification for Seismic Test of Buildings.

[19] Q. J. Pan, Experimental Study on Seismic Capacity of Precast Prestressed Concrete Frame Structures, Southeast University, Nanjing, China, 2006.

[20] R. Park, "Evaluation of ductility of structures and structural assemblages from laboratory testing," Bulletin of the New Zealand National Society for Earthquake Engineering, vol. 22, no. 3, pp. 155-166, 1989.

[21] D. Zenunović and R. Folić, "Models for behaviour analysis of monolithic wall and precast or monolithic floor slab connections," Engineering Structures, vol. 40, pp. 466-478, 2012.

[22] G. Y. Ma and Y. P. Su, "Calculation formulas for ultimate compressive strength and strain of FRP confined concrete cylinder," Journal of Hebei University of Science and Technology: Natural Science Edition, no. 1, pp. 74-77, 2010.

[23] L. Zeng, Research on Seismic Behaviors And Design Method of Steel Reinforced High Strength And High Performance Concrete Frame Joints [Ph.D. thesis], Xi'an University of Architecture and Technology, Xi'an, China, 2008. 


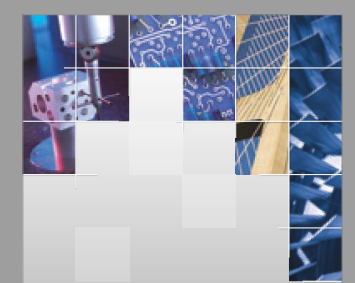

\section{Enfincering}
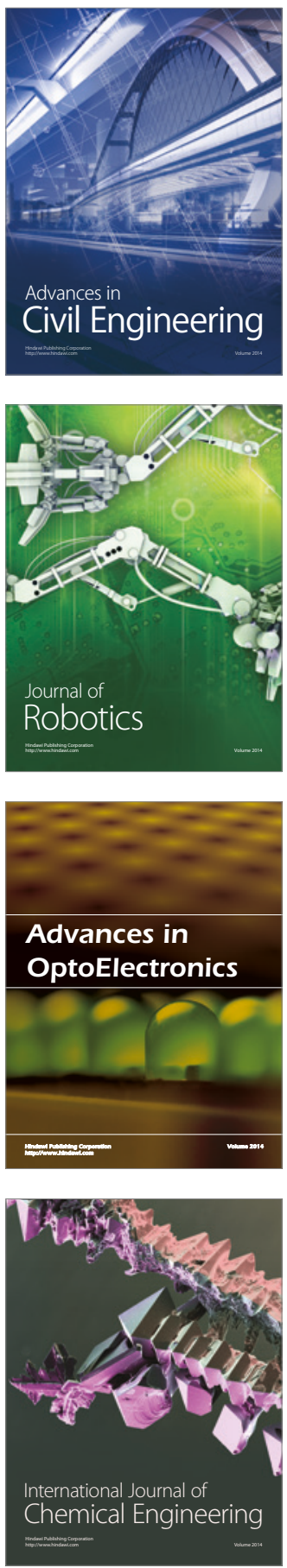

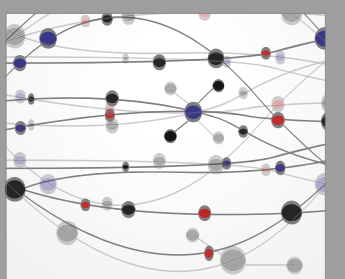

The Scientific World Journal

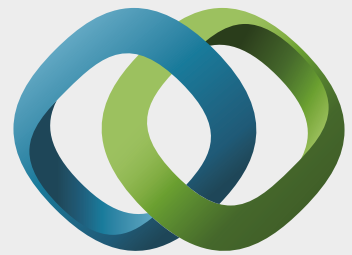

\section{Hindawi}

Submit your manuscripts at

https://www.hindawi.com
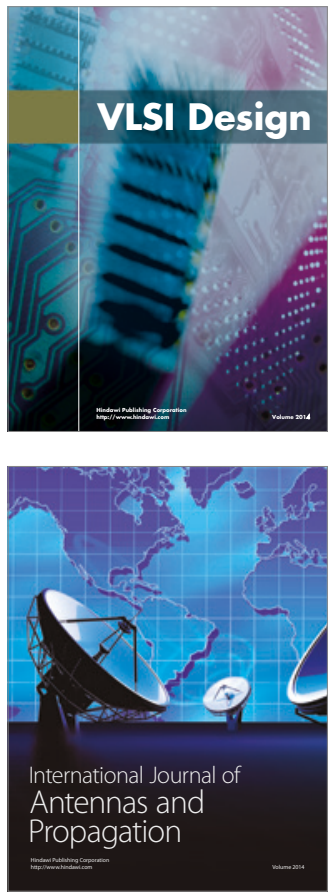

\section{Rotating}

Machinery
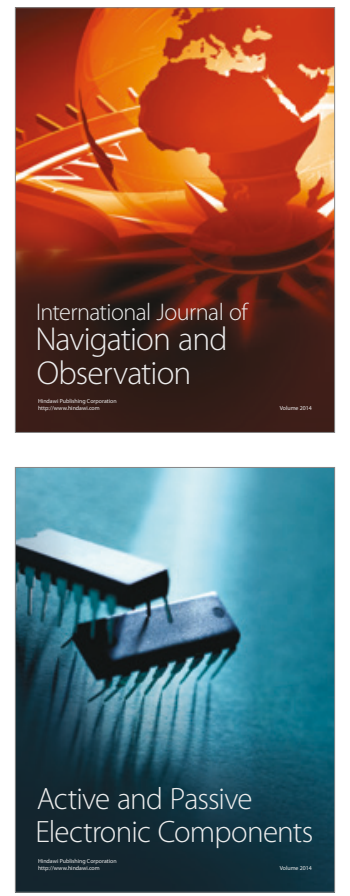
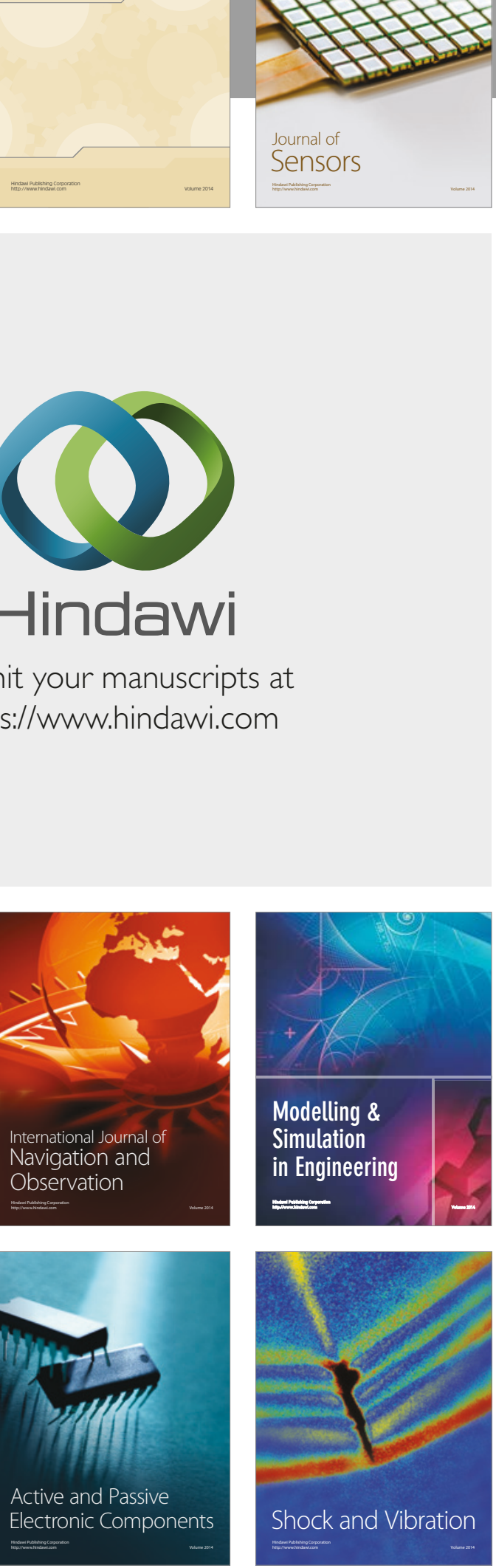
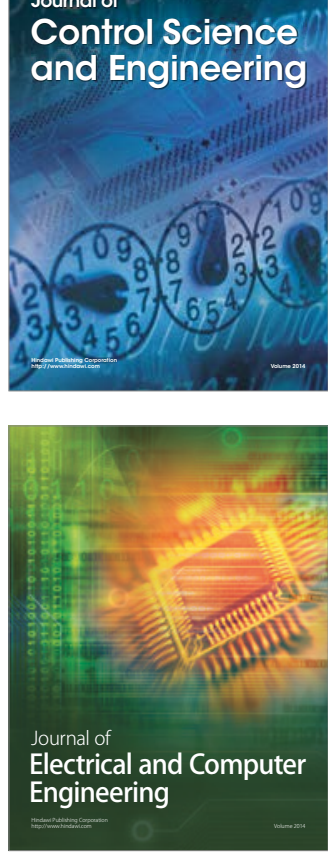

Distributed

Journal of

Control Science

and Engineering
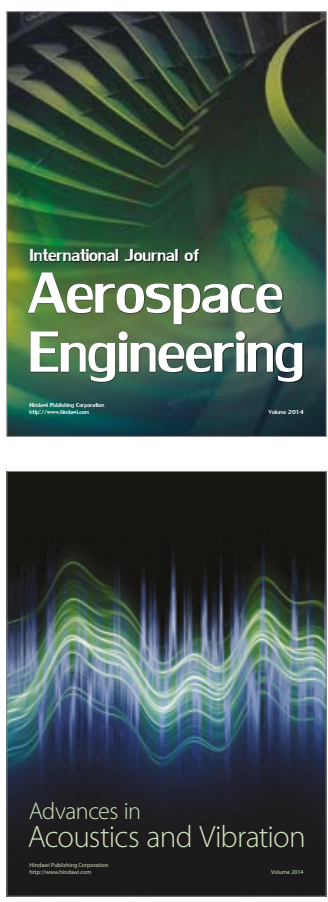

Sensor Networks 